SOCIAL RESEARCH REPORTS

ISSN: 2066-6861 (print), ISSN: 2067-5941 (electronic)

\title{
NURSING CORE CURRICULUM REVISION IN ISRAEL: HISTORICAL REVIEW
}

\author{
Rachel KEMELMAN, Daniela COJOCARU
}

Social Research Reports, 2019, Vol. 11, Issue 3, pp. 90-96

The online version of this article can be found at:

www. researchreports.ro

\section{https://doi.org/10.33788/srr11.3.6}

Published by:

Expert Projects Publishing House

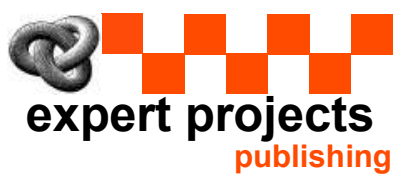

Covered by Index Copernicus International www.indexcopernicus.com

Directory of Open Access Journals

www.doaj.org

On behalf of:

Center for Program and Social Development

Aditional services and information about Social Research Reports can be found at:

www.researchreports.ro 


\title{
NURSING CORE CURRICULUM REVISION IN ISRAEL: HISTORICAL REVIEW
}

\author{
Rachel KEMELMAN ${ }^{1}$, Daniela COJOCARU ${ }^{2}$
}

\begin{abstract}
The Nursing Core Curriculum has been continually developed and revised in many countries over recent decades. These revisions are shaped mainly by social changes and challenges: for example, the forecast that the elderly will become a significant percentage of populations in developed countries, global migration processes, computerization of medical services, and new complex medical devices have all necessitated changes in the education of $21^{\text {st }}$ century nurses. In Israel, nursing education has developed simultaneously under the influences of both the British versus the American core curricula through the last century. The latest Core Curriculum was published in 2012, and for the last three years, the Ministry of Health Nursing Administration have been working on the development of a new core. Meanwhile, all nursing education institutions are expected to implement de-facto changes which are supervised by the Ministry of Health's audit tool development and inspection process.
\end{abstract}

Keywords: nursing education, core curriculum, social change, implementation process.

\section{Historical Review on the development of the Nursing Core Curriculum}

The establishment of secular nursing education was largely the initiative of Florence Nightingale, the "Lady with the Lamp" from the Crimean war (1854-56) (Cook, 2018). Later development of nursing education was based on two different approaches: the European paradigm saw nursing as an occupation while the American paradigm saw nursing as a discipline and envisaged the establishment of a profession (Parse, 1999). These differences also affected the approach to nursing education, which was either hospital-based or conducted in academic institutions. In Europe, doctors trained nurses to perform specific tasks. Hospitalaffiliated programs trained nurses and received a costless workforce for a few years (Rafferty, 1995). According to the American approach, nursing students were

${ }^{1}$ Ziv Nursing School, ISRAEL; Department of Sociology and Social Work, Alexandru Ioan Cuza University, Iasi, ROMANIA. E-mail: rachel.kemelman@gmail.com

2 Department of Sociology and Social Work, Alexandru Ioan Cuza University, Iasi. ROMANIA. E-mail: dananacu@gmail.com 
trained for the nursing profession in an educational center, by nursing educators. This latter approach was considered a very revolutionary approach to nursing education (Zwanger, 1968).

In Britain, topics of nursing education, such as enrollment, licensing and certification were the subject of debate between those who desired to maintain the superiority of hospital administration concerns in the determination of employment conditions, and those who aspired to turn nursing into a free profession, that could demand its own charges and service conditions. Another controversial question revolves around the extent to which the nurse should be competent in technical versus moral skills. Many nursing leaders regarded technical skills and knowledge as inferior to the personal nature and moral values of nursing, even to the extent that some doctors considered book learning unnecessary for the nursing training process (Rafferty, 1995).

The above dispute has continued to prevail during the academization of nursing education. In the USA, the first academic setting for nurses' higher education was opened in 1899 in the Columbia University Teachers' College, serving as a role model for academic nursing programs in other American universities and colleges in the following years (Kalisch, \& Kalisch, 1995). In Australia, the first academic program for nurses was established in 1940. Nevertheless, many decades passed until in the 1970s in the USA and 1990s in Australia, academic nursing programs grew into the standard educational pattern for nursing education. The American Nursing Association (ANA) stipulated that an academic degree was the condition for a nursing license in 1965 (Ashley, 1976), and a similar condition was adopted in Australia, in the $21^{\text {st }}$ century.

Contrastingly, in Europe academization of nursing appeared far later. For example, the first academic programs for nurses appeared in the UK in the 1960s, but up to $96 \%$ of UK nurses achieved only a diploma level program in 2005-2006. One reason for this phenomenon was the fact that an academic degree was not required for license registration in England. The other reasons include the fact that there was little advantage for better employment positions or professional recognition with an academic degree in nursing. This can be compared to Scotland and Wales that have attempted to establish a policy requiring an academic degree as an obligatory minimum demand for nursing license registration (Shields, \& Watson, 2007).

A more comprehensive overview of this issue indicates that a very few academic programs were established in Europe for nursing education during the $20^{\text {th }}$ century, as follows: in Austria and Germany - in the 1960s, Holland - in the 1980s and Switzerland - in the 1990s. Clift (1997) explained this disparity between the numbers of academic nursing education programs in Europe versus the USA as the result of the traditional approach of European Universities, which do not promote the development of applied science. 


\section{Nursing core curriculum aspects: Discussion through the years}

There has been continuous debate concerning various issues in the nursing curriculum and nursing education programs through the decades. For example, the relative influence of humanities on nursing education and the integration of these aspects and contents into the core curriculum. There has also been discussion concerning the influence of the nurse's own value system, and the development of their competence to distinguish their own experiences and values from those of the others with whom they work and communicate every day (such as patients, doctors, families, etc.), and their ability to integrate and empathize with dissimilar values (Wilson, 1974).

The evolution of nursing from being mentored by doctor's demands to the development of an independent healthcare profession can be followed through the prism of nursing textbooks as they evolved through the years. Frederiksen (2010) performed just such an analysis and revealed how physicians had significantly influenced the format of nursing education in Denmark from 1870 to 1956 (from 1957 the Danish nursing education program was regulated by its own statutory order). Frederiksen (2010) gave examples indicating that the nurse was not perceived as an independent professional but "as the doctor's far-sighted helper" (p.158). He showed how the educational process reflected in those early textbooks was designed by the physician's viewpoint on essential nurse responsibilities. It is clear that there was much deliberation concerning the knowledge needed for nurses to enhance their practice. The textbook of Bertha Harmer (1922) became the guiding rulebook for generations of nursing educators. The main concept of Harmer's model of nursing practice was an emphasis on "human needs". Boschma, Davidson and Bonifacio (2009) described the evolution of those "human needs" and the way in which they altered through the decades as portrayed in the textbooks, noting the influence of cultural-historical contexts on their evolution.

\section{1th Century Demands and Nursing Education}

Major challenges in the development of the modern healthcare system have led to changes in the approach to nursing education, which in turn require the adaptation of the nursing curriculum (Schekel, 2016). The most relevant aspects, which reflect challenges encountered in nursing practice and necessitate adjustment of the nursing education program include: a significant increase in life expectancy and a growing aging population percentage, the process of population exchange and migration that requires a culturally competent healthcare system, greater refinement in medical technological tools and devices.

Research has examined the adequacy of gerontology contents in nursing education programs in Belgium (Deschodt, de Casterlé, \& Milisen, 2010), and guidelines were developed to encourage nursing educators to qualify students 
to give appropriate care to the aging population in the USA (Thornlow, Latimer, Kingsborough, \& Arietti, 2006). Also in Canada, research has been used to inform attempts to improve the quality of gerontology teaching in BA nursing programs (McCleary, McGilton, Boscart, \& Oudshoorn, 2009). Another significant example of challenges in nursing practice, relates to the improvement of the patient's safety by decreasing the incidence of medical mistakes. How can these needs be met? The issue of safety should be integrated in the nursing education program in a new, creative way. Researchers have suggested that traditional methods of coping with students' errors do not contribute to increasing awareness to safety-enhancing behaviors (Gregory, Guse, Dick, \& Russell, 2007).

\section{Nursing Core Curriculum Development and Revisions}

Most textbooks and research relating to the nursing core curriculum development and revision are derived from USA based nursing education. There are also studies that were conducted in other countries, for example European countries (Collins, \& Hewer, 2014), China (Deng, 2015), and Canada (Anthony, \& Landeen, 2009; Iwasiw, Goldenberg, \& Andrusyszyn, 2009; Iwasiw, \& Goldenberg, 2014). There is a significant variety of nursing educational programs, different regulation requirements for professional nursing certification, and several different curriculum design strategies that differentiate nursing education in different countries. There have been attempts in European countries to introduce standardization in higher nursing education, due to the Bologna process influences on nursing education in these countries (Collins, \& Hewer, 2014),

In Romania in 1976, Ceausescu's anti-intellectual policy led to the closure of schools of nursing and also academic social work and physiotherapy departments. Romania suffered a serious shortage of qualified registered nurses for decades after this act, and nursing education was limited to practitioner nursing. In the 1990s a 3-year nursing core curriculum based on the Australian design was selected by the Head nurse of Romania and the Ministry of Health (Lakey, Nicholas, Wolg, \& Leuner, 1996). Ecaterina Gulie (2011) the president of the RNA (Romanian Nurses Association) stated that the changes in nursing education and nurses' status in Romania started as a part of Romania's preparations to enter the European Union in the 1990s, thus the EU standards for nursing education were adopted. The RNA and the Romanian Ministry of Health worked in collaboration with international experts from Denmark and WHO to develop a new nursing core curriculum. According to current WHO data, Romania offers nursing education at three levels: diploma, B.A. and M.A. degrees (Praxmarer-Fernandes, Maier, Oikarainen, Buchan, \& Perfilieva, 2017). 


\section{Development of the Nursing Core Curriculum in Israel}

The first nursing school was established in 1918 in Palestine by the Hadassah American medical unit, although, the nursing school structure was an amplification of the structure established by Dr. Kagan a few years before. The fundamental issue debated through the years after this is whether a nursing school should be based on the traditional European pattern (doctors prepared nurses to execute particular duties) or on the fresh and revolutionary perception of qualifying students for the nursing profession in an academic education center (the "American model nursing school"), whose graduates are acknowledged and approved by the government as qualified professionals (Zwanger, 1968).

Zwanger (1968) asserted that those who developed the nursing education system in Israel did not achieve the goals they dreamed of in regard to the level of education nor did they succeed in producing significant numbers of graduates. Thus, the nursing education programs were unable to meet the requirements of the newly founded country and its dynamically increasing population. Zwanger (1968) claimed that a few fundamental errors led to this failure. The first was the selection of the foreign nursing core curriculum programs without proper adjustment to local circumstances and barriers. The second was the overuse of nursing students at hospital departments as unpaid work power instead of investing in their theoretical learning. The third mistake was a lack of proper qualification for nursing teachers.

Over the last century, the main social challenges faced by Israel have included the absorption of large waves of immigrants, a series of wars with neighboring states, and the growth of many culturally diverse communities. These challenges have placed serious demands on Israel's nursing services and consequently influenced the development of the nursing core curriculum. For example, the acute shortage of nurses in 1948-52 prompted the acceleration of short-term education programs for the qualification of practical nurses, simultaneously lowering the admission criteria for registered nurses' education programs. Later in the 1960s and 1970s the field of nursing education underwent reorganization in order to improve the quality of graduates' qualification. These changes included the development of an updated and extended core curriculum and updating and refining admission requirements (Bergman, 1986).

The first academic nursing program was opened in the University of Tel-Aviv in 1968. Since then nursing schools have gained increased autonomy following their budgetary separation from hospitals. University-escorted panels upgraded curricula and courses to academic level in many nursing schools, thus preparing the ground for a further process that would affiliate the nursing schools to universities. Registered nurses were offered an option to enroll in academic post-basic programs in order to raise their academic level to a BA degree. These changes improved clinical practice training (Bergman, 1986).

At the beginning of the $21^{\text {st }}$ century, nursing administration departments began to publish annual activity reports on the Israeli Ministry of Health Internet site. The adaptation of nursing education programs to the demands of this period is 
clearly reflected in these reports. For example, special re-education programs were organized for immigrant nurses with foreign certification as a response to the shortage of nurses following a large influx of more than a million immigrants from the USSR in the 1990s (Nursing Administration Annual Report, [MOH], 2001). Further efforts to cope with the shortage of nurses during the first decade of the new millennium generated more revision of the core curriculum in 2012. Many courses and hours were cut from the core in order to reduce the study program to a 2-year retraining program for B.A. graduates from any academic discipline. However, this revision, cut some essential courses from the core, such as the reduction of academic hours for transcultural nursing, anatomy and physiology (Nursing Administration Policy Guideline \#91, [MOH], 2011).

\section{Conclusion}

However, in the last three years, a new Chief Nurse and the Health Ministry's Nursing Administration Department have again begun a process for revision of the core curriculum. In 2017, the advisory committee to the Nursing Administration Department worked with delegates from all nursing education programs in Israel to understand which revisions were needed for the nursing core curriculum. In 2018, the nursing administration department introduced de-facto stipulations to the core curriculum to be inspected by an audit of all nursing education programs. In March 2019, the draft copy of the new core curriculum was distributed to all nursing education programs and the heads of nursing institutions and nursing school directors were asked to send their objections to the Nursing Administration Department. In the annual program of the Nursing Administration Department, the publication of a new core was planned for the first trimester of 2019, but has now been postponed to June-July 2019 (Ministry of Health, 2019).

\section{References}

Anthony, S. E., \& Landeen, J. (2009). Evolution of Canadian nursing curricula: A critical retrospective analysis of power and caring. International Journal of Nursing Education Scholarship, 6(1), 1-14.

Ashley, J. A. (1976). Hospitals, Paternalism and the Role of the Nurse.| New York: Teachers College Pres

Boschma, G., Davidson, L., \& Bonifacio, N. (2009). Bertha Harmer's 1922 textbook - The Principles and Practice of Nursing: clinical nursing from an historical perspective. Journal of clinical nursing, 18(19), 2684-2691.

Clift, J. M. (1997). Nursing Education in Austria, Germany, and Switzerland. Journal of Nursing Scholarship, 29(1), 89-92.]

Collins, S., \& Hewer, I. (2014). The impact of the Bologna process on nursing higher education in Europe: a review. International Journal of Nursing Studies, 51(1), 150-156.

Cook, E. T. (2018). The Life of Florence Nightingale (Vol. 1). BoD-Books on Demand.

Gregory, D. M., Guse, L. W., Dick, D. D., \& Russell, C. K. (2007). Patient safety: where is nursing education? Journal of Nursing Education, 46(2).? 
Greenlaw, B. A. (1983). Curriculum implementation in general nursing diploma programs in British Columbia (MA dissertation, Theses (Faculty of Education)/Simon Fraser University).

Gulie, E. (2011). The history of nursing in Romania. Nursing History Review, 19, 175.

Frederiksen, K. (2010). A discourse analysis comparing Danish textbooks for nursing and medical students between 1870 and 1956. Nursing Inquiry, 17(2), 151-164.]

Deschodt, M., de Casterlé, B. D., \& Milisen, K. (2010). Gerontological care in nursing education programmes. Journal of Advanced Nursing, 66(1), 139-148.

Deng, F. F. (2015). Comparison of nursing education among different countries. Chinese Nursing Research, 2, 96-98.

Kalisch, P. A., \& Kalisch, B. J. (1995). The advance of American nursing. Lippincott Williams \& Wilkins.?

Nursing Administration, Ministry of Health [MOH], State of Israel (2019). Nursing Administration Annual Plan for 2019. Retrieved 23, April, 2019, from: https:// www.health.gov.il/PublicationsFiles/nr_annual2019.pdf

Nursing Administration, Ministry of Health [MÖH], State of Israel (2011). Update of nursing core curriculum for registered nurses. Nursing Administration Policy Guideline \# 91, 5/12/2011. Retrieved 31, May, 2018, from: https://www.health. gov.il/hozer/ND91_11.pdf

Nursing Administration, Ministry of Health [MOH], State of Israel (2001). Annual Report of Nursing Administration Department towards 2002. Retrieved 31, May, 2018, from: https://www.health.gov.il/PublicationsFiles/nr_2001.pdf

McCleary, L., McGilton, K., Boscart, V., \& Oudshoorn, A. (2009). Improving gerontology content in baccalaureate nursing education through knowledge transfer to nurse educators. Nursing leadership, 22(3).?

Lakey, C. K., Nicholas, P. K., Wolf, K. A., \& Leuner, J. D. M. (1996). Health care and nursing in Romania. Journal of advanced nursing, 23(5), 1045-1049.

Parse, R. R. (1999). Nursing: The discipline and the profession. Nursing Science Quarterly, 12 (4), 275-276.

Praxmarer-Fernandes ${ }^{1}$, S., Maier, C. B., Oikarainen, A., Buchan, J., \& Perfilieva, G. (2017). Original Research. Levels of education offered in nursing and midwifery education in the WHO European region: multicountry baseline assessment. PANORAMA, 418.

Rafferty, A. M. (1995). Art, science and social science in nursing: occupational origins and disciplinary identity. Nursing Inquiry, 2(3), 141-148.

Scheckel, M. (2016). Designing courses and learning experiences. In Billings, D.M., \& Halstead, J.A. (Eds.), Teaching in nursing: A guide for faculty (pp. 159-186). St. Louis, MO: Elsevier.

Thornlow, D., Latimer, D., Kingsborough, J., \& Arietti, L. (2006). Caring for an aging America: A guide for nursing faculty. Washington, DC: American Association of Colleges of Nursing.!

Shields, L., \& Watson, R. (2007). The demise of nursing in the United Kingdom: a warning for medicine. Journal of the Royal Society of Medicine, 100(2), 70-74.

Wilson, H. S. (1974). A case for humanities in professional nursing education. Nursing Forum, 13(4) 406-417.

Zwanger, L. D. (1968). Preparation of Graduate Nurses in Israel, 1918-1965. (PhD dissertation), Columbia University. 